\title{
Detail Design and Construction Procedure of Laminar Soil Containers for Experimental Shaking Table Tests
}

\author{
Hamid Reza Tabatabaiefar*
}

\begin{abstract}
In this study, a comprehensive procedure for detail design and construction of laminar soil containers has been developed and presented for practical applications in shaking table tests. A laminar soil container is a flexible container that can be placed on a shaking table to simulate vertical shear-wave propagation during earthquakes through a soil layer of finite thickness and can realistically simulate the free field conditions in comparison with other types of soil containers. The presented laminar soil container consists of aluminium frames and rubber layers in alternating pattern as the container main construction materials. The aluminium frames provide lateral confinement of the soil while the rubber layers allow the container to deform in a shear beam manner. The designed and constructed container satisfies the conditions required to authentically capture free field ground motion. The lateral movements of the container in shaking table tests expected to be almost identical to the free field movements in reality. In addition, natural frequency of the constructed soil container, measured from Sine Sweep tests, matches the targeted natural frequency with acceptable accuracy.
\end{abstract}

Keywords: Laminar Soil Container, Shaking Table Tests, Free Field Ground Motion, Sine Sweep Tests

\section{INTRODUCTION}

Geotechnical models cannot be directly mounted on shaking tables due to the requirements of confinement. To model the soil in shaking table tests, a container is required to hold the soil in place. In literature, this container is referred to as "Soil Container", "Soil Tank", or "Shear Stack". During the past few decades, several researchers have carried out shaking table tests on soilstructure systems using various types of soil containers and structural models. Soil containers can be categorised into three main categorise, namely, rigid, flexible, and laminar containers. Most of recent experimental shaking table tests over the past 10 years (e.g. Jakrapiyanun, 2002; Prasad et al., 2004; Pitilakis et al., 2008; Chau et al., 2009; Tang et al., 2009; Turan et al., 2009; Chen et al., 2010; Lee et al., 2012; Tabatabaiefar et al., 2014) have been performed using laminar soil containers due to their accuracy in modelling realistic site conditions. However, none of the past research works presented design and construction procedure of laminar soil containers. As a result, in order to employ laminar soil containers in testing programmes, researchers may need to spend substantial amount of time to properly design and produce construction detail drawings for their laminar soil containers. In response to this need, in this study, a comprehensive procedure for

* Lecturer in Civil Engineering, School of Engineering and Information Technology, Faculty of Science and Technology, Federation University Australia, Tel.: +61 35327 6718; E-mail address: h.tabatabaiefar@federation.edu.au 
detail design and construction of laminar soil containers has been developed and presented for practical applications in shaking table test programmes.

\section{BACKGROUND}

Rigid containers are the simplest type consisting of no moving parts. According to Jakrapiyanun (2002), studying earth retaining structures such as retaining walls, bridge abutments, and quay walls seems to be appropriate on rigid wall containers as the soil on one side of the earth retaining structure is lower than the other side. Therefore, the soil on the shallower depth is less restricted. The main drawback to rigid containers is distorting the free field boundary conditions. This occurs because firstly the rigid walls cannot move along with soil, and secondly there are excessive energy reflections from their boundaries. In order to provide the free field conditions in this type of container, an extremely large container is required which is not feasible in most cases. Another option to reduce the reflecting energy is to attach energy absorbing layers to the container walls. Steedman and Zeng (1991) concluded that only one third of incident waves could reflect from these kinds of absorbent boundaries. Despite the fact that using absorbent boundaries decreases the reflection of outward propagating waves back into the model from the boundary walls, those boundaries may cause additional modelling variables like stiffness and friction of the layers (Gohl and Finn, 1987). Valsangkar et al. (1991) employed 25-mm thick Styrofoam as the absorbing layers in their rigid container. The layers were attached to both end walls perpendicular to the shaking direction. Reimer et al. (1998) modelled four types of containers and clearly demonstrated the disability of rigid containers in modelling the free field conditions. Flexible containers allow the modelled soil inside them to move more analogous to the natural conditions of the free field in comparison with rigid containers. In addition, reflection of outward propagating waves back into the model from the walls could be reduced more efficiently. An example for flexible soil containers is a flexible cylindrical soil container designed by Meymand (1998).

A laminar soil container is a flexible container that can be placed on a shaking table to simulate vertical shear-wave propagation during earthquakes through a soil layer of finite thickness. Gazates (1982) pointed out that laminar soil containers can realistically simulate the free field conditions in comparison with rigid and flexible containers. Several types of inter-layer sliding systems for 
laminar soil containers have been used over the past few decades such as commercial ball bearings (Ishimura et al., 1992), sliding systems such as Teflon (Chau et al., 2009), and elastic materials such as rubber (Taylor, 1997).

Taylor (1997) designed a laminar soil container having inside dimensions of $5 \mathrm{~m}$ length, $1 \mathrm{~m}$ width, and $1.15 \mathrm{~m}$ height made of rectangular aluminium frames. Small rubber blocks were inserted between frames with $0.5 \mathrm{~m}$ spacing in the longitudinal sides. The noticeable and major points of modelling techniques utilised by Taylor (1997) are as follows:

- As the same tuning stiffness for the container and the soil is required in the desired strain level, and based on the selected maximum strain level for the soil, the natural frequency of the soil was determined. Afterwards, the natural frequency of empty container was fitted to the estimated natural frequency of the soil;

- Sand was glued to the base of the container and end walls to provide frictional contact between the soil and container's base and end walls; and

- The estimated weight of the container was $33 \%$ of the soil weight. It is preferable to reduce this portion as much as possible.

By satisfying the above conditions in design of Taylor's laminar soil container, authentic conditions of the free field ground motion could be captured in shaking table tests. Thus, lateral movements of the container in shaking table tests may be almost identical to the free field movements in reality. Many researchers (e.g. Gazetas, 1982; Taylor et al., 1995; Pitilakis et al., 2008; Tang et al., 2009) concluded that laminar soil containers are the most advanced and efficient type of the soil containers. Based on the conclusions made by the above mentioned researchers, the merits of adopting laminar soil containers in shaking table tests over the other types of soil containers are as follows:

- Well-designed laminar soil containers can better model the free field conditions in comparison with rigid and flexible containers as the lateral deformations in laminar soil containers are almost identical to the free field movements;

- Uniform lateral motion exists in each horizontal plane; and

- Lateral motion of the entire depth follows the sinusoidal shape which represents authentic conditions of the free field ground motion.

With respect to the above mentioned merits of using laminar soil containers over the other types 
of containers (flexible and rigid soil containers) and in order to perform rigorous and reliable experimental shaking table tests, laminar soil containers are the best option to be employed in testing programmes.

\section{PROTOTYPE CHARACTERISTICS}

The prototype of the experimental tests is a soil-structure system with dimensional characteristics illustrated in Figure 1. The prototype building frame of the soil-structure system is a two dimensional fifteen storey concrete moment resisting frame. The building frame height and width are 45 and 12 metres, respectively and spacing between the frames into the page is 4 metres. The building is resting on a footing which is 4 meters wide and 12 meters long. The natural frequency of the prototype building is $0.384 \mathrm{~Hz}$ and its total mass is 953 tonnes. Soil medium underneath the structure is a clayey soil with shear wave velocity of $200 \mathrm{~m} / \mathrm{s}$ and soil density of $1470 \mathrm{~kg} / \mathrm{m}^{3}$. Horizontal distances of the soil lateral boundaries and bedrock depth have been selected to be 60 metres (five times the width of the structure) and 30 metres, respectively.

\section{SCALING FACTORS FOR SHAKING TABLE TESTING}

Scale models can be defined as having geometric, kinematic, or dynamic similarities to the prototype (Langhaar, 1951; Sulaeman, 2010). Geometric similarity defines a model and prototype with homologous physical dimensions. Kinematic similarity refers to a model and prototype with homologous particles at homologous points at homologous times. Dynamic similarity describes a condition where homologous parts of the model and prototype experience homologous net forces. Moncarz and Krawinkler (1981) explained that scale models meet the requirements of similitude to the prototype to differing degrees, and researchers may apply nomenclature such as "true", "adequate", or "distorted" to the model. A true model fulfils all similitude requirements. An adequate model correctly scales the primary features of the problem, with secondary influences allowed to deviate while the prediction equation is not significantly affected. Distorted models refer to those cases in which deviation from similitude requirements distorts the prediction equation, or where compensating distortions in other dimensionless products are introduced to preserve the prediction equation.

In addition, Moncarz and Krawinkler (1981) elucidated that in 1-g scale modelling, where, $\rho$ is density, $E$ is modulus of elasticity, $a$ is acceleration, and $g$ is gravitational acceleration, the dimensionless product $a / g$ (Froude's number) must be kept equal to unity implying that the ratio 
of model to prototype specific stiffness $(E / \rho)$ is equal to the geometric scaling factor $\lambda$. This is known as "Cauchy condition" which can also be stated in terms of shear wave velocity as follows:

$\frac{\left(V_{S}\right)_{p}}{\left(V_{S}\right)_{m}}=\sqrt{\lambda}$

where, subscripts $p$ and $m$ stand for prototype, and model, respectively, and $V_{s}$ is shear wave velocity.

In addition, Moncarz and Krawinkler (1981) showed that satisfying the Cauchy condition is a necessary requirement for simultaneous replication of restoring forces, inertial forces, and gravitational forces in a dynamic system.

Iai (1989) derived a comprehensive set of scaling relations for a soil-structure system under dynamic loading and defined the entire problem in terms of geometric, density, and strain scaling factors. This method relates the geometric $(\lambda)$ and density $\left(\lambda_{p}\right)$ scaling factors, and then derives the strain scaling factor $\left(\lambda_{\varepsilon}\right)$ from shear wave velocity tests on both the model and prototype soil, as presented in Equation (2).

$$
\lambda_{\varepsilon}=\left[\frac{\lambda}{\left(\frac{\left(V_{S}\right)_{p}}{\left(V_{S}\right)_{m}}\right)^{2}}\right]
$$

Meymand (1998) and Moss et al (2010) explained that no governing equation can be written describing the entire soil-structure system, nor can dimensional analysis or similitude theory be directly applied to this complex system to achieve "true" model similarity. The viable scale modelling approach for application of scale model similitude, therefore, consists of identifying and successfully modelling the primary forces and processes in the system, while suppressing secondary effects, thereby yielding an "adequate" model.

Several researchers (e.g. Meymand, 1998; Turan et al., 2009, Moss et al., 2010) pointed out that in order to achieve an adequate model for dynamic soil-structure interaction simulation in shaking table tests, Cauchy condition (Equation 1), should be satisfied. In addition, the strain scaling factor $\left(\lambda_{\varepsilon}\right)$ should be kept equal to one. It should be noted that when Cauchy condition is satisfied, obviously, 
the result of substituting the value of $\left(V_{s}\right)_{p} /\left(V_{s}\right)_{m}$ from Equation (1) into Equation (2) is equal to one. The objective of the scale modelling procedure for this test program is to achieve "dynamic similarity", where model and prototype experience homologous forces. For this purpose, adopted methodology by Meymand (1998) is the framework for scale model similitude in this study. According to this approach, three principal test conditions establish many of the scaling parameters. The first condition is that testing is conducted in a 1 -g environment, which defines model and prototype accelerations to be equal. Secondly, a model with similar density to the prototype is desired, fixing another component of the scaling relations. Thirdly, the test medium is primarily composed of saturated clayey soil, whose undrained stress-strain response is independent of confining pressure, thereby simplifying the constitutive scaling requirements. In addition to the three principal test conditions, Meymand (1998) pointed out that the natural frequency of the prototype should be scaled by an appropriate scaling relation. By defining scaling conditions for density and acceleration, the mass, length, and time scale factors can all be expressed in terms of the geometric scaling factor $(\lambda)$, and a complete set of dimensionally correct scaling relations (ratio of prototype to model) can be derived for all variables being studied. The scaling relations for the variables contributing to the primary modes of system response are shown in Table 1 (Meymand, 1998; Turan et al., 2009; Moss et al., 2010; Sulaeman, 2010; Lee et al., 2012; Tabatabaiefar, 2012; Tabatabaiefar et al., 2014).

In Table 1 , the shear wave velocity scaling factor $\left(\left(V_{s}\right)_{p} /\left(V_{s}\right)_{m}\right)$ is equal to $\lambda^{1 / 2}$. Therefore, Cauchy condition (Equation 1) is met in the scaling relations. In addition, strain scaling factor $\left(\lambda_{\varepsilon}\right)$, which can be determined by substituting the value of $\left(V_{s}\right)_{p} /\left(V_{s}\right)_{m}$ from Equation (1) into Equation (2), is kept equal to one. Thus, as mentioned earlier, both requirements for achieving an adequate model for dynamic soil-structure interaction simulation in shaking table tests are satisfied.

\section{ADOPTED GEOMETRIC SCALING FACTOR}

Adopting an appropriate geometric scaling factor $(\lambda)$ is one of the important steps in scale modelling on shaking table. Although small scale models could save cost, the precision of the results could be substantially reduced. Therefore, to attain the largest achievable scale model which represents the most accurate results possible, geometric scaling factor $(\lambda)$ has been selected 
with respect to the following limitations of the employed uni-axial shaking table as the design criteria:

- $\quad$ Size of the table : $3 \mathrm{~m} \times 3 \mathrm{~m}$

- Maximum payload : $10,000 \mathrm{~kg}$

- Overturning moment : $100 \mathrm{kN}-\mathrm{m}$

Table 2 compares the characteristics of the scale model shown in Figure 2 for different scaling factors. In this table, the related weight is just accounted for soil inside the tank excluding weights of the container and structure. As previously mentioned, a model with similar density to that of the prototype is desired in order for the dynamic similarity to be satisfied. As a result, soil unit weight in the model and prototype should be the same and equal to $14.40 \mathrm{kN} / \mathrm{m}^{3}$. In addition, the ratio between width and length of the soil container is another variable to be considered. According to the previously designed containers (e.g Gazetas, 1982; Taylor, 1997; Pitilakis et al., 2008; Chau et al., 2009), ratio of 2:3 between width and length of the soil container is deemed to be the most appropriate ratio. Thus, this ratio has been adopted in this study. Referring to Tables 1 and 2, with respect to the design criteria, scaling factor of 1:30 provides the largest achievable scale model with rational scales, maximum payload, and overturning moment which meet the facility limitations. Thus, geometric scaling factor $(\lambda)$ of $\mathbf{1 : 3 0}$ is adopted for experimental shaking table tests on the scale model in this study.

\section{CHARACTERISTICS OF LAMINAR SOIL CONTAINER}

Referring to Table 2, by selecting 1:30 as the geometric scaling factor, the container should have minimum length, width, and depth of $2.0 \mathrm{~m}, 1.20 \mathrm{~m}$, and $1.0 \mathrm{~m}$, respectively. Allowing a further 10 mm on each side for construction purposes similar to Prasad et al. (2004), the final length $\left(L^{*}\right)$, width $\left(W^{*}\right)$, and depth $\left(D^{*}\right)$ of the laminar soil container are estimated to be $2.10 \mathrm{~m}, 1.30 \mathrm{~m}$, and $1.10 \mathrm{~m}$, respectively (Figure 3).

In terms of choosing the materials to build the soil container, according to the previous conducted research works (e.g. Ishimura et al., 1992; Taylor, 1997; Jakrapiyanun, 2002; Pitilakis et al., 2008; Chau et al., 2009), aluminium frames and rubber layers were employed in an alternating pattern. Therefore, the laminar soil container consists of a rectangular laminar box made of aluminium rectangular hollow section frames separated by rubber layers. The aluminium frames provide 
lateral confinement of the soil, while the rubber layers allow the container to deform in a shear beam manner.

\section{DETAIL DESIGN OF LAMINAR SOIL CONTAINER}

Taylor et al. (1995) stated that the mass and stiffness characteristics of the soil container should be carefully chosen so that the container's natural frequency and mode shapes in horizontal shear are compatible with those of the contained soil. The primary aims of the design are to ensure that the soil mass controls the overall dynamic response of the soil-container system, and the soil mass is subjected to the simple shear boundary conditions that exist in the idealised prototype system. In this system, horizontal soil strata overlaying rigid bedrock and the lateral boundaries are at infinity. When subjected to horizontal bedrock movements, the soil responds like a shear beam as horizontal shear waves propagate vertically, leading to a sinusoidal lateral displacement profile.

According to Table 1, scaling factor between shear wave velocity of the soil model $\left(V_{s}\right)_{m}$ and shear wave velocity of the prototype soil $\left(V_{s}\right)_{p}$ can be expressed as follows:

$$
\frac{\left(V_{s}\right)_{m}}{\left(V_{s}\right)_{p}}=\lambda^{1 / 2}=0.182
$$

Knowing that the shear wave velocity of the prototype soil $\left(V_{s}\right)_{p}$ is $200 \mathrm{~m} / \mathrm{s}$ from Section 4.2 , the shear wave velocity of the soil model $\left(V_{s}\right)_{m}$ can be determined from Equation (3):

$$
\left(V_{s}\right)_{m}=0.182 \times\left(V_{s}\right)_{p}=0.182 \times 200=36.4 \mathrm{~m} / \mathrm{s}
$$

According to Kramer (1996), natural frequency of the subsoil $\left(f_{s}\right)$ can be calculated from the following relationship:

$$
f_{s}=\frac{V_{s}}{4 H_{s}}
$$

where, $V_{s}$ is the shear wave velocity of the subsoil and $H_{s}$ is the bedrock depth.

Thus, the natural frequency of the soil model $\left(f_{m}\right)$ can be determined by substituting the values of the shear wave velocity $\left(V_{s}\right)_{m}$ and bedrock depth $\left(H_{s}\right)_{m}$ of the soil model equal to $36.4 \mathrm{~m} / s$ and $1 \mathrm{~m}$, respectively, in Equation (4): 
$f_{m}=\frac{\left(V_{s}\right)_{m}}{4\left(H_{s}\right)_{m}}=\frac{36.4}{4 \times 1}=9.1 H z$

With respect to the required dimensions of the soil container, a numerical 3D model of the laminar soil container has been built in SAP2000 software using one dimensional frame elements to model aluminium rectangular hollow section frames and two dimensional shell elements to model rubber layers as shown in Figure 4. The numerical model comprises ten aluminium rings and nine rubber layers. Afterwards, the mass and stiffness characteristics of the soil container have been designed in a way that the container and soil model natural frequencies match. For this purpose, size and mechanical properties of the aluminium rectangular hollow section frames and rubber layers were determined in design process after several cycles of trial and error in a way that the natural frequency of the model soil $\left(f_{m}=9.1 \mathrm{~Hz}\right)$ with the natural frequency of the laminar soil container match together.

The final arrangement and construction details of the laminar soil container are depicted in the construction detail drawings (Figures 5 to 8). In the construction detail drawings, all the dimensions are in millimetres. Figure 5 shows the soil container general plan and the arrangement of the rubber layers. The current arrangement for $40 \times 40 \mathrm{~mm}$ flexible rubbers in plan, were introduced in the design in order to provide low elastic stiffness and low natural frequency for the container. It also reduces the problem of the container being too stiff relative to the soil at high shear strains. The base of the container is a timber hardwood plate with eight $40 \mathrm{~mm}$ diameter holes. The container can be fixed and secured on the shaking table using eight M38 bolts passing through the provided holes as shown in Figure 6. In addition, six horizontal timber plates $(\mathrm{PL} 1800 \times 50 \times 25 \mathrm{~mm})$ have been utilised underneath the timber base plate as the stiffeners to increase the bending capacity of the base plate and ease the transportation of the container (Figure 6).

The first aluminium ring resting on the base plate, with length and width of $2.10 \mathrm{~m}$ and $1.30 \mathrm{~m}$, respectively, is referred to as the base frame. This base frame is fixed to the timber base plate with twelve M20 bolts grade 4.6, according to AS/NZS 3678-2011, with minimum length of $80 \mathrm{~mm}$ (Figure 7). In this way, connection between the timber base plate and the rest of the container is provided. The capacities of all the utilised bolt connections of the container were checked for tension and shear in accordance with AS/NZS 3678-2011. Connections between aluminium rectangular hollow section frames and rubbers are provided using strong Megapoxy 69 glue. Megapoxy 69 is a 
clear non-sag gel type epoxy structural adhesive for bonding metals to metals, metals to concrete and masonry, assembly of granite and marble fabrications, and many other civil engineering applications requiring superior bond strengths. Figure 8 illustrates the utilised aluminium frame sections, rubber sizes, long section of the container, and connection details between different components of the container.

\section{CONSTRUCTION OF LAMINAR SOIL CONTAINER}

As the first step, aluminium rectangular hollow sections were cut and drilled according to the detail drawings (Figure 9a). Then, cut and drilled aluminium sections were welded so as to form the required aluminium rectangular frames for the laminar soil container construction (Figure 9b). Using hardwood timber plates, according to construction detail drawing of the base plate (Figure 6), timber base plate was constructed utilising slim diameter hardwood nails. Then, the prepared base frame was placed on top of the timber base plate and used as the pattern for drilling the holes which are required for connecting the base plat to the base frame. Afterwards, M20 grade 4.6 bolts were passed through the holes and fastened to provide a fix connection between the base plate and the base frame (Figure 10a). In the next step, rubber sections were placed and glued on top of the base frame according to the general plan as shown in Figure 5 using Megapoxy 69 glue. By gluing aluminium rectangular frames and rubbers in a successive manner, the walls of the container have been built up (Figure 10b) until the wall construction is completed (Figure 11).

\section{TESTING AND SETUP}

The first step in setting up the main phase of the shaking table tests, was securing the constructed laminar soil container on shaking table. For this purpose, the soil container was placed at the designated location, then fixed and secured on the shaking table using eight M38 bolts passing through the provided holes. The internal surface of the soil container was then covered and sealed with two layers of black plastic sheeting. Similar to Gohl and Finn, (1987) and Valsangkar et al. (1991), $25 \mathrm{~mm}$ thick absorbing layers of Polystyrene foam sheets have been installed at the end walls of the soil container to simulate viscous boundaries in the free field condition. The thick layers of Polystyrene minimise reflection of outward propagating waves back into the model and allow the necessary energy radiation. In addition, a layer of well graded gravelly soil particles were glued to the bottom of the soil container so as to simulate frictional contact between the soil and the bedrock. 
This layer provides friction between the timber base plate, as the bedrock, and the in-situ soil mix and does not allow the soil mix to slip over the base plate. Various components of the laminar soil container are shown in Figure 12.

In order to determine fundamental natural frequency of the built soil container, Sine Sweep tests have been performed. Sine Sweep tests involve logarithmic frequency sweep holding specified acceleration constants at the base of the structure. For the current Sin Sweep tests, exponential sine sweep wave with amplitude of $0.05 \mathrm{~g}$, exponential increase rate of $0.5 \mathrm{~Hz} / \mathrm{min}$., and frequency range of $1-50 \mathrm{~Hz}$ was performed to the empty laminar soil container to estimate the natural frequency of the container. The first resonance between the shaking table and structural model frequencies showed the fundamental natural frequency of the model. After three times repeating the test, the natural frequency of the container was found to be $10 \mathrm{~Hz}$. The difference between the obtained natural frequency of the container and the natural frequency of the soil, calculated during original design of the laminar soil container (equal to $9.1 \mathrm{~Hz}$ ) is approximately $10 \%$ which is acceptable. It can be seen that all Taylor's conditions (Taylor, 1997) are satisfied in the design and construction of the laminar soil container. Therefore, it can capture authentic conditions of the free field ground motion in shaking table tests and lateral movements of the container in shaking table tests are expected to be almost identical to the free field movements in reality.

\section{SUMMARY AND CONCLUSIONS}

This study outlines detail design and construction method of a laminar soil container to be used in shaking table tests. A numerical 3D model of the laminar soil container has been created using one dimensional frame elements to model aluminium rectangular hollow section frames and two dimensional shell elements to model rubber layers. Then, size and mechanical properties of the aluminium rectangular hollow section frames and rubber layers were determined in design process after several cycles of trial and error. Based on the design outcomes, the final arrangement and construction details of the laminar soil container have been proposed and illustrated in laminar soil container construction detail drawings.

The final length, width, and depth of the laminar soil container have been estimated to be $2.10 \mathrm{~m}$, $1.30 \mathrm{~m}$, and $1.10 \mathrm{~m}$, respectively. Aluminium frames and rubber layers were employed in an alternating pattern as the container construction materials. The aluminium frames provide lateral 
confinement of the soil, while the rubber layers allow the container to deform in a shear beam manner. Connections between aluminium rectangular hollow section frames and rubbers are provided using strong Megapoxy 69 glue which is a clear non-sag gel type epoxy structural adhesive for bonding metals to metals. The base of the aluminium frames has been connected to the timber base plate, made of hardwood, using M20 grade 4.6 bolts in order to provide a fix connection between the base plate and the base frame.

The internal surface of the soil container has been covered and sealed with two layers of black plastic sheeting and $25 \mathrm{~mm}$ thick absorbing layers of Polystyrene foam sheets have been installed at the end walls of the soil container to simulate viscous boundaries in the free field condition. A layer of well graded gravelly soil particles were glued to the bottom of the soil container which will provide friction between the timber base plate, as the bedrock, and the in-situ soil mix and does not allow the soil mix to slip over the base plate. In order to determine fundamental natural frequency of the constructed soil container, Sine Sweep tests have been performed and repeated three times. Based on the test results, the natural frequency of the container was found to be $10 \mathrm{~Hz}$ which is very close to calculated natural frequency during original design of the laminar soil container. The laminar soil container, with the presented details, satisfies Taylor's conditions (Taylor, 1997). Therefore, it can capture authentic conditions of the free field ground motion while lateral movements of the container in shaking table tests are expected to be almost identical to the free field movements in reality. 


\section{References}

AS/NZS 3678-2011, Structural Steel - Hot-rolled plates, floor plates and slabs, Australian Standards, Sydney.

Chau, K.T., Shen, C.Y. \& Gou, X. 2009, 'Nonlinear Seismic Soil-Pile-Structure Interactions: Shaking Table Tests and FEM Analyses', Soil Dynamics and Earthquake Engineering, vol. 29, no. 29, pp. 300-310.

Chen, J., Shi, X. \& Li, J. 2010, 'Shaking Table Test of Utility Tunnel under Non-uniform Earthquake Wave Excitation', Soil Dynamics and Earthquake Engineering, vol. 30, no. 11, pp. 1400-1416.

Gazetas, G. 1982, 'Vibrational Characteristics of Soil Deposits with Variable Wave Velocity', International Journal for Numerical and Analytical Methods in Geomechanics, vol. 6, no. 1, pp. 1-20.

Gohl, W.B. \& Finn, W.D.L. 1987, 'Seismic Response of Single Piles in Shaking Table Studies', Proceedings of the Fifth Canadian Conference Earthquake Engineering, p. 435-444.

Jakrapiyanun, W. 2002, 'Physical Modeling of Dynamics Soil-Foundation-Structure-Interaction Using a Laminar Container', PhD thesis, University of California, San Diego.

Iai, S. 1989, 'Similitude for Shaking Table Tests on Soil-Structure-Fluid Model in 1g Gravitational Field', Soils and Foundations, vol. 29, no. 1, pp. 105-118.

Ishimura, K., Ohtsuki, A., Yoloyama, K. \& Koyanagi, Y. 1992, 'Sway-rocking Model for Simulating Nonlinear Response of Sandy Deposit with Structure', Proceedings of the Tenth World Conference on Earthquake Engineering, pp. 1897-1903.

Kramer, S.L. 1996, Geotechnical Earthquake Engineering, Prentice Hall civil engineering and engineering mechanics series, ISBN 0-13-374943-6.

Langhaar, H. 1951, Dimensional Analysis and Theory of Models, John Wiley \& Sons Inc., New York.

Lee, CH., Wei, Y. \& Huo, Y. 2012, 'Boundary Effects of a Laminar Container in Centrifuge Shaking Table Tests', Soil Dynamics and Earthquake Engineering, vol. 34, no. 1, pp. 37-51.

Meymand, P.J. 1998, 'Shaking Table Scale Model Tests of Nonlinear Soil-Pile-Superstructure Interaction in Soft Clay', PhD thesis in Civil Engineering, University of California, Berkeley.

Moncarz, P. \& Krawinkler, H. 1981, Theory and Application of Experimental Model Analysis in Earthquake Engineering, Report No. 50, John Blume Earthquake Engineering Ctr., Stanford Univ.

Moss, R.E.S., Crosariol, V. \& Kuo, S. 2010, 'Shake Table Testing to Quantify Seismic Soil-Structure Interaction of Underground Structures', Proceedings of the 5th International Conference on Recent Advances in Geotechnical Earthquake Engineering and Soil Dynamics, May 24-29, San Diego, Paper No. $1.27 \mathrm{~b}$.

Prasad, S., Towhata, I., Chandradhara, G. \& Nanjundaswamy, P. 2004, 'Shaking Table Tests in Earthquake Geotechnical Engineering', Current science, vol. 87, no. 10, pp. 1398-1404. 
Pitilakis, D., Dietz, M., Wood, D.M., Clouteau, D. \& Modaressi, A., 2008, 'Numerical Simulation of Dynamic Soil-Structure Interaction in Shaking Table Testing', Soil Dynamics and Earthquake Engineering, vol. 28, pp. 453-467.

Riemer, M., Gookin, W., Bray, J. \& Wartman, J. 1998, 'Using Reflected Waves to Measure Small Strain Dynamic Properties', Proceedings of the 5th Caltrans Seismic Research Workshop, Sacramento, pp. 16-18.

Steedman, R.S. \& Zeng, X. 1991, 'Physical Modelling of Earthquake Excitation for Geotechnical Engineering', Proceedings of the $6^{\text {th }}$ Canadian Conference Earthquake Engineering, pp. 285-295.

Sulaeman, A. 2010, 'The Use of Lightweight Concrete Piles for Deep Foundation on Soft Soils', PhD thesis in Civil Engineering, University of Tun Hussein Onn, Malaysia.

Tabatabaiefar, S.H.R. 2012, 'Determining Seismic Response of Mid-rise building Frames Considering Dynamic Soil-Structure Interaction', PhD Thesis, University of Technology Sydney (UTS), Australia.

Tabatabaiefar, H.R., Fatahi, B., \& Samali, B. 2014, 'Numerical and Experimental Investigations on Seismic Response of Building Frames under Influence of Soil-Structure Interaction', Advances in Structural Engineering, vol. 17, no. 1, pp. 109-130, Multi-Science Publishing.

Tang, L., Ling, X., Xu, P., Gao, X. \& Wang, D. 2009, 'Shake Table Test of Soil-Pile Groups-bridge Structure Interaction in Liquefiable Ground', Earthquake Engineering and Engineering Vibration, vol. 9, no. 1, pp. 1-12.

Taylor, C.A. 1997, Large Scale Shaking Tests of Geotechnical Structures, Earthquake Engineering Research Centre, University of Bristol.

Taylor, C.A., Dar, A.R. \& Crewe, A. J. 1995, 'Shaking Table Modelling of Seismic Geotechnical Problems', Proceedings of the 10th European Conference on Earthquake Engineers, Vienna, Austria, pp. 441-446.

Turan, A., Hinchberger,S. \& El Naggar, H. 2009, 'Design and Commissioning of a Laminar Soil Container for Use on Small Shaking Tables', Soil Dynamics and Earthquake Engineering, vol. 29, no. 2, pp. 404414.

Valsangkar, A.J., Dawe, J.L. \& Mita, K.A. 1991, 'Shake Table Studies of Seismic Response of Single Partially Supported Piles', Proceeding of the $6^{\text {th }}$ Canadian Conference Earthquake Engineering, pp. 327-334. 


\section{Dear Journal Manager,}

Enclosed is a manuscript of technical paper titled "Detail Design and Construction Procedure of Laminar Soil Containers for Experimental Shaking Table Tests" by Hamid Reza Tabatabaiefar to be considered for publication in International Journal of Physical Modelling in Geotechnics.

There is no financial interest to report and I certify that the submission is original work and is not under review at any other publication.

I hope that the editorial board will agree on the interest of this study.

Yours sincerely,

\section{Dr Hamid Reza Tabatabaiefar}

06/10/2015 


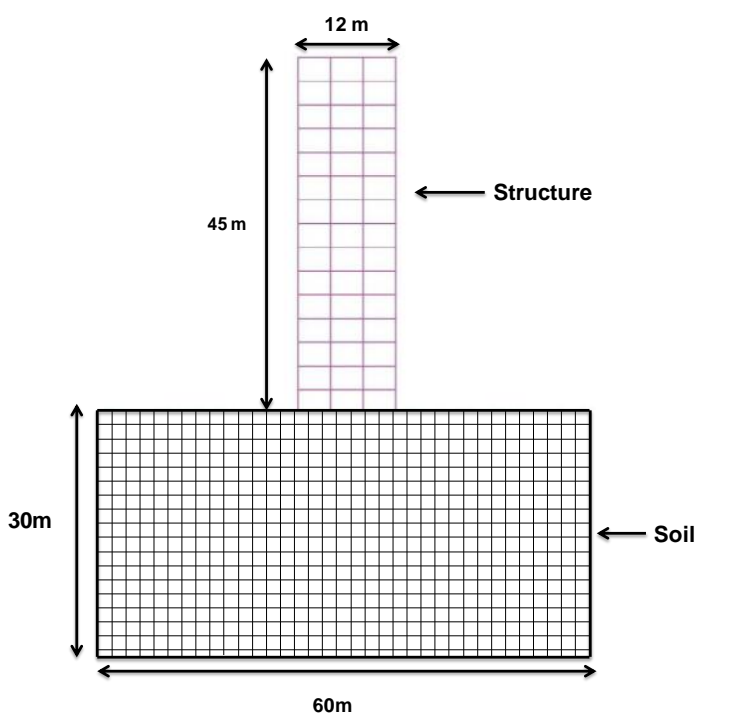

Figure 1: Dimensional characteristics of the prototype

\author{
The
}




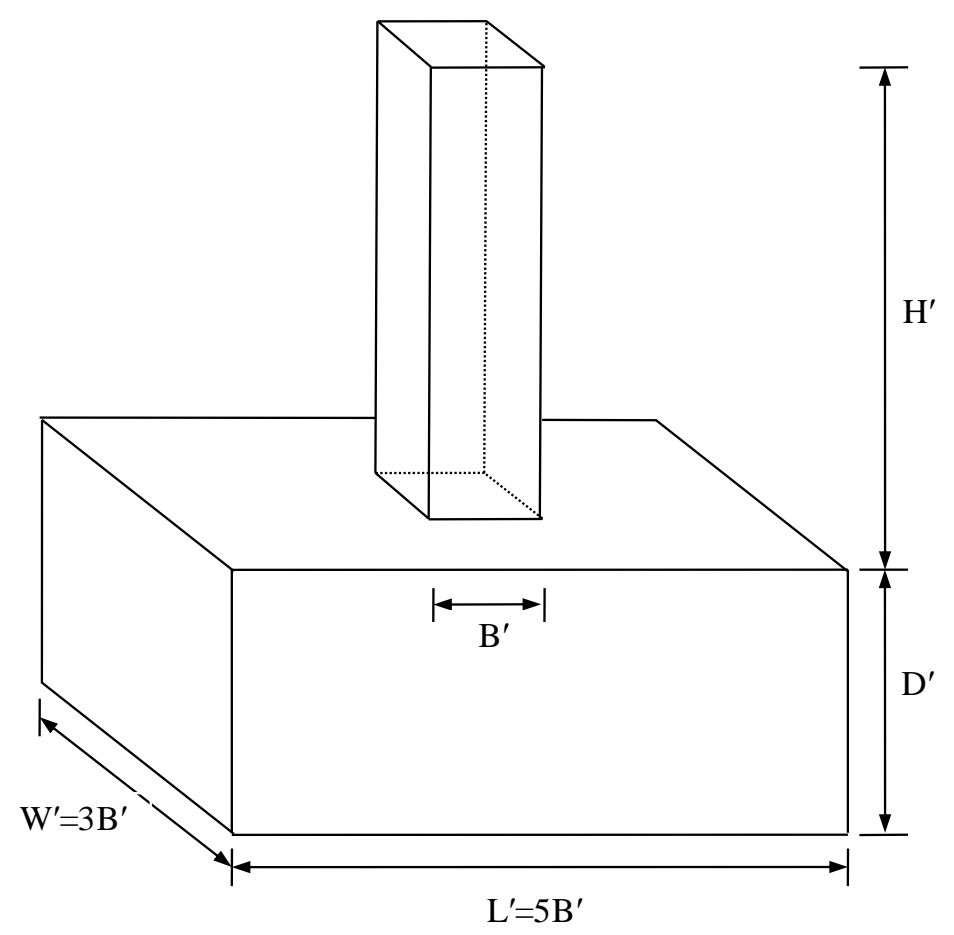

Figure 2: Scale model of soil structure interaction problem 


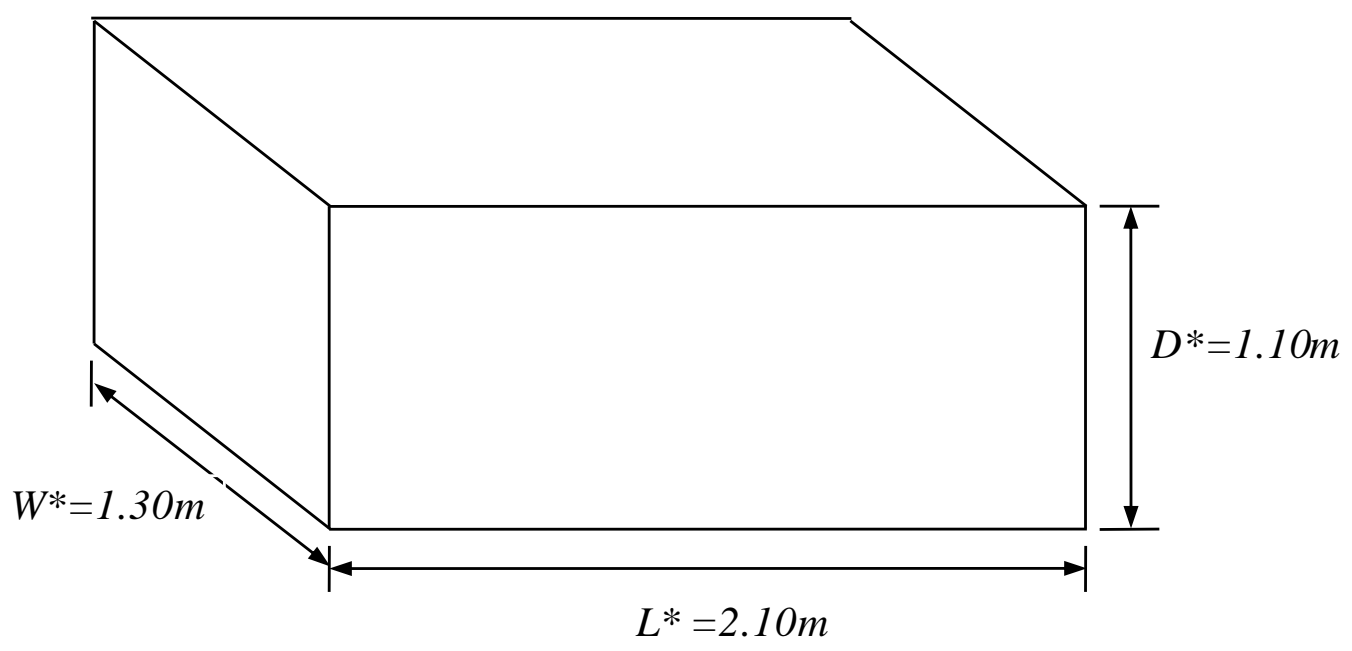

Figure 3: Adopted laminar soil container dimensions 


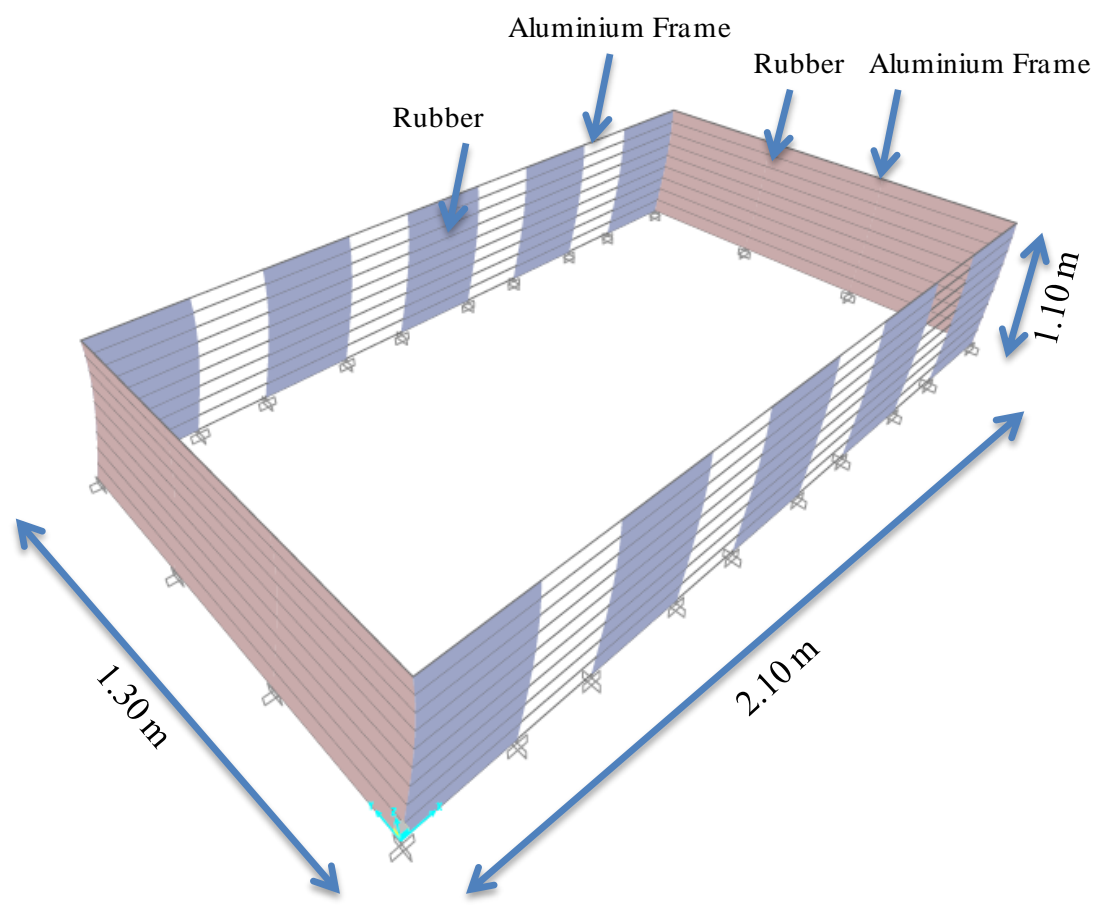

Figure 4: 3D numerical model of the laminar soil container in SAP2000 


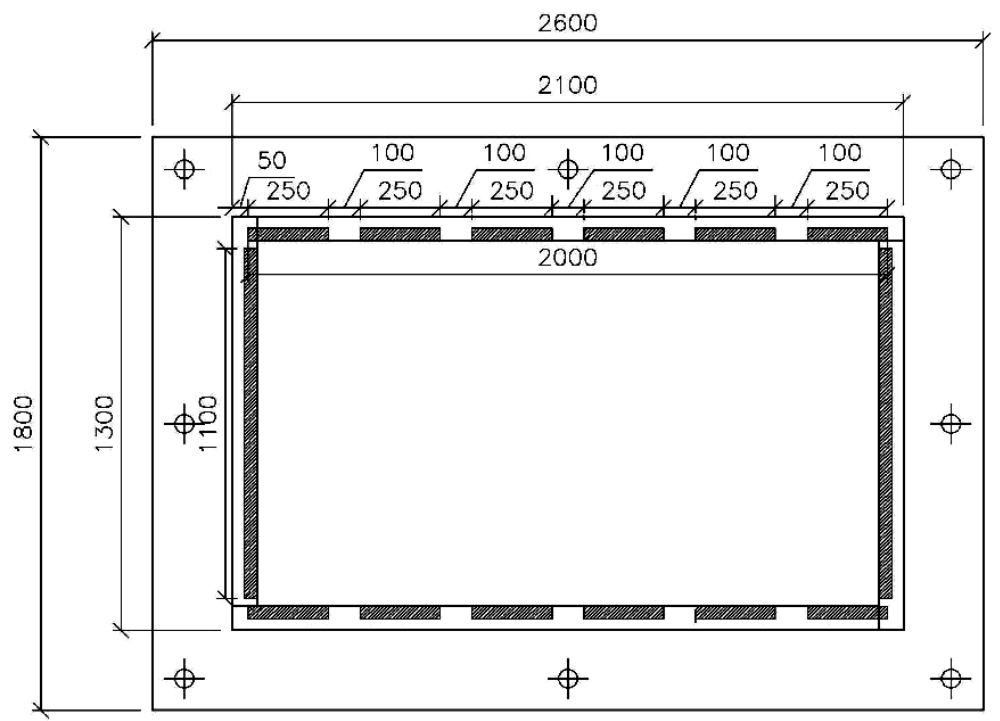

Figure 5: Laminar soil container general plan 


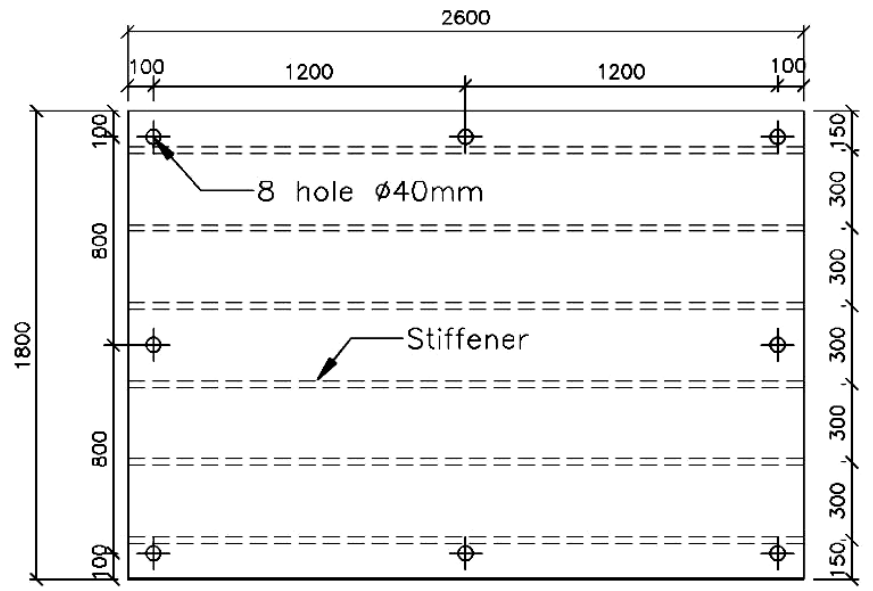

Figure 6: Construction detail drawing of the hardwood timber base plate 


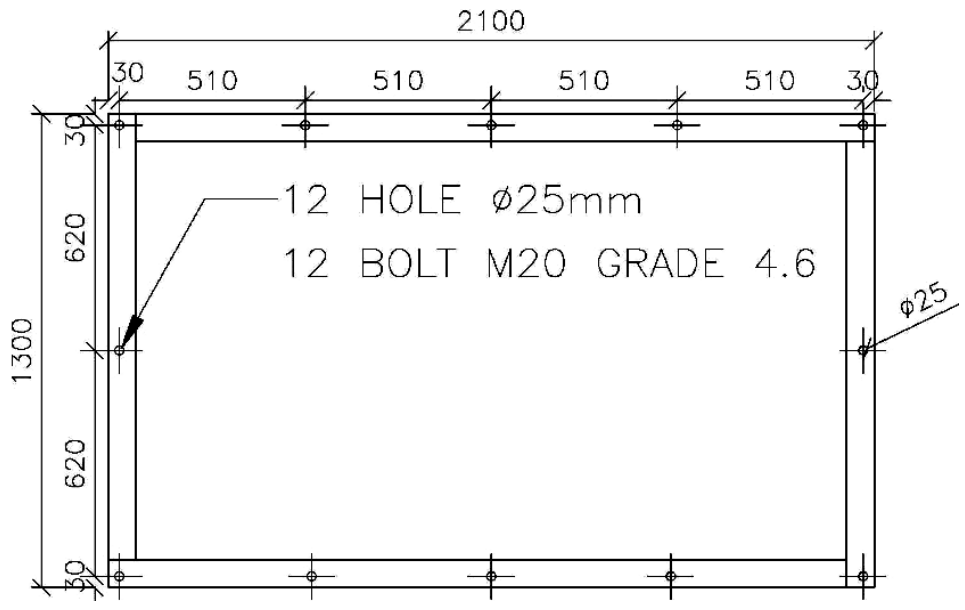

Figure 7: Construction detail drawing of the aluminium base frame 


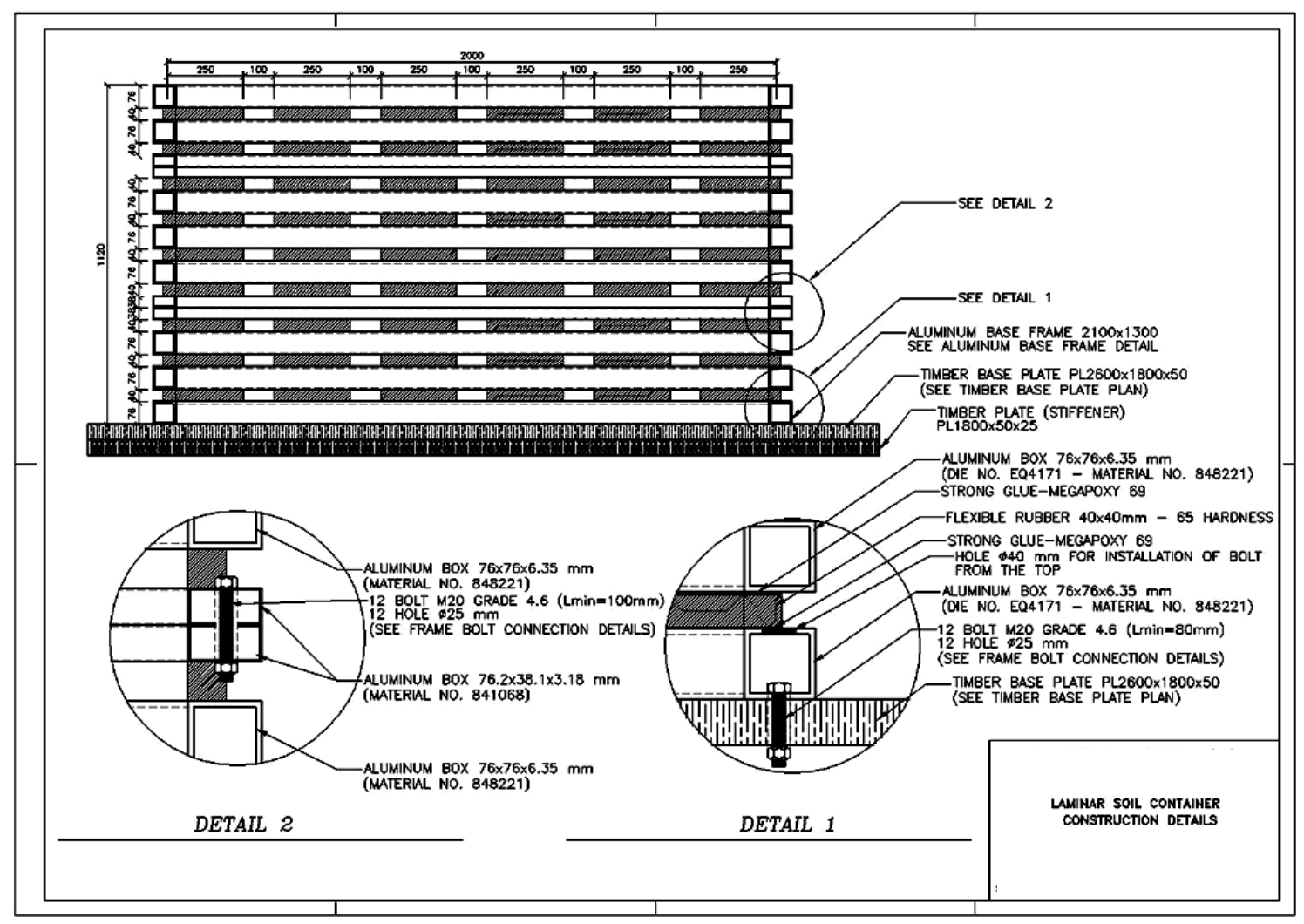

Figure 8: Construction detail drawing of the connections 


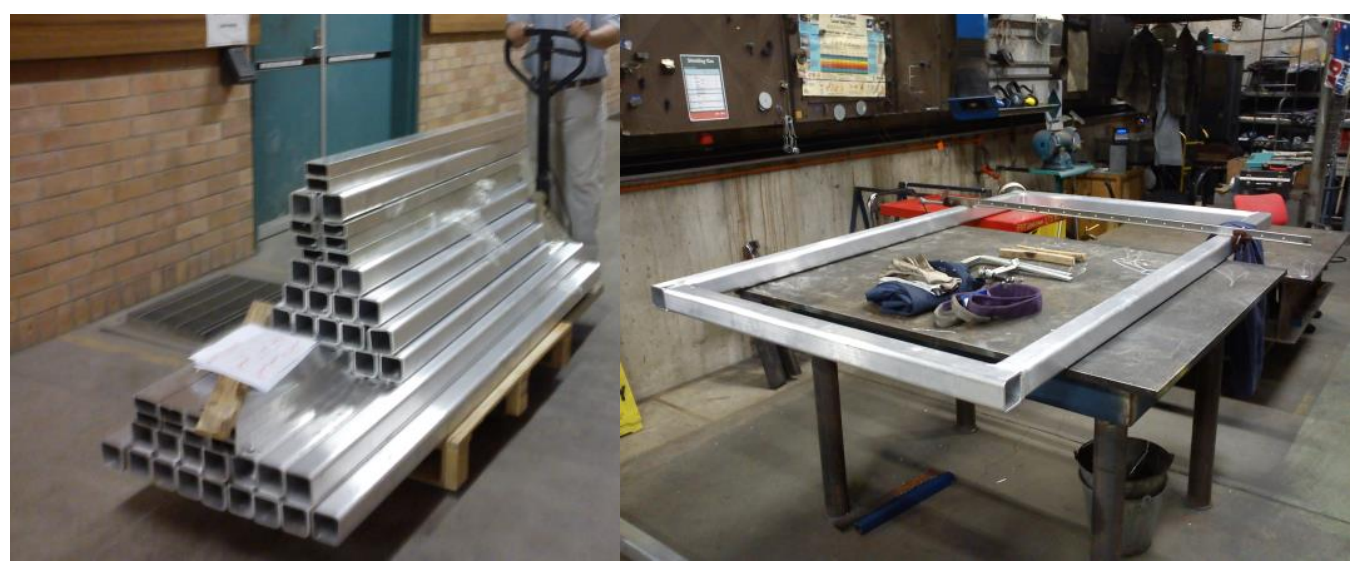

(a)

(b)

Figure 9: (a) Cut and drilled aluminium sections; (b) ready to use welded rectangular aluminium frames 


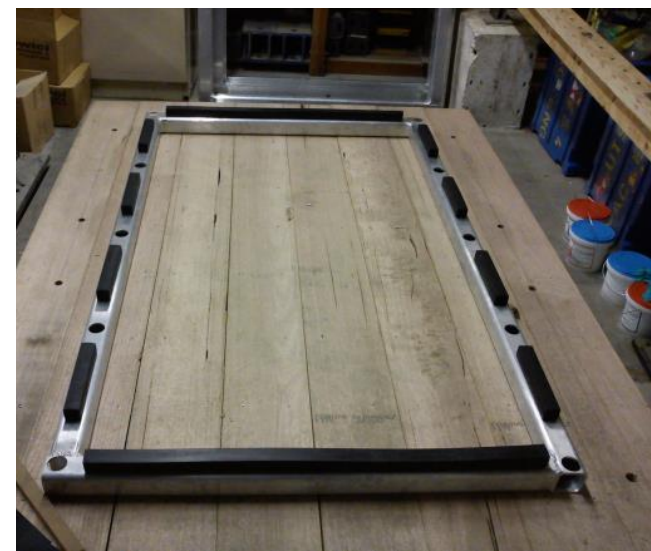

(a)

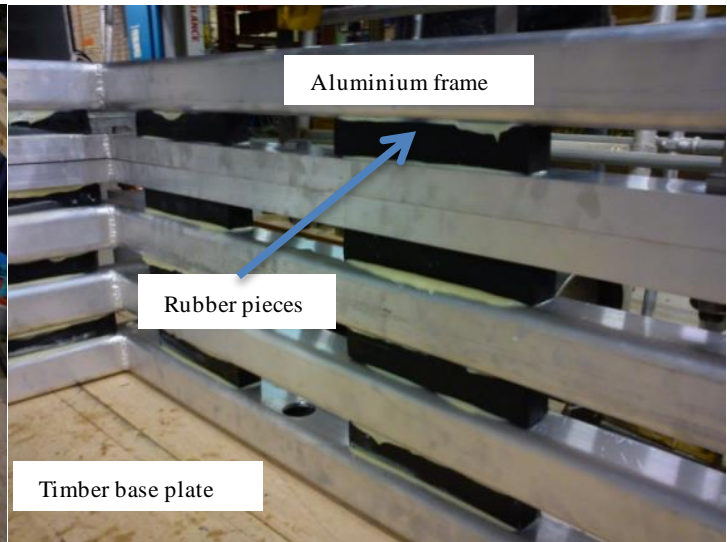

(b)

Figure 10: (a) Bolted connection between the base plate and base frame; (b) soil container walls consisting of glued aluminium frames and rubbers 


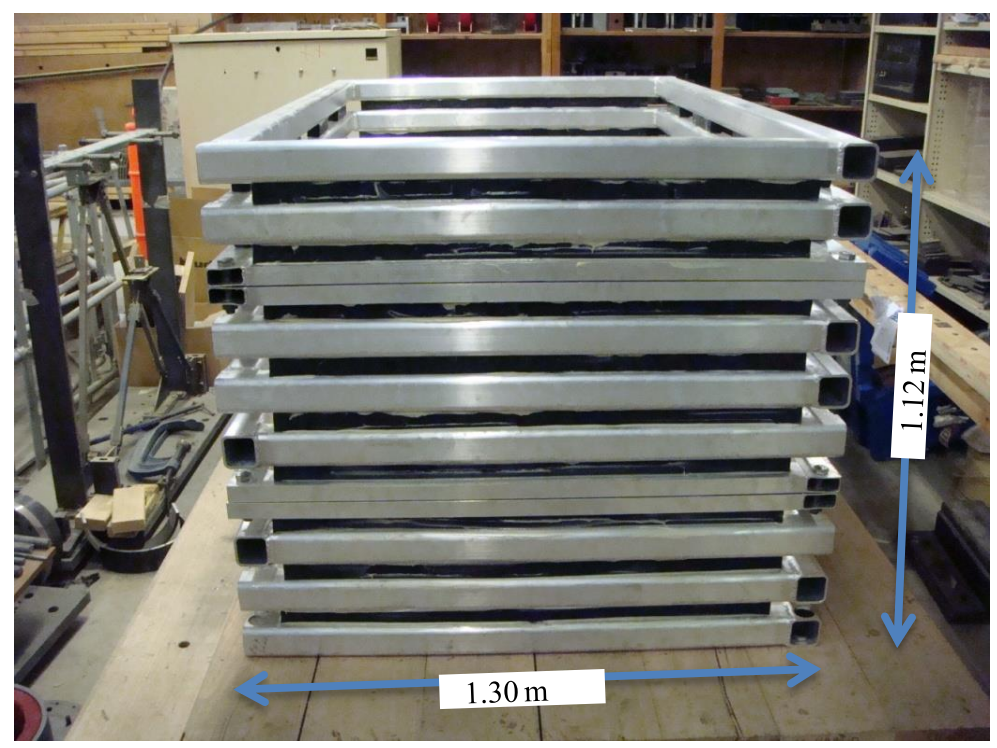

Figure 11: Laminar soil container view after completion of the walls 


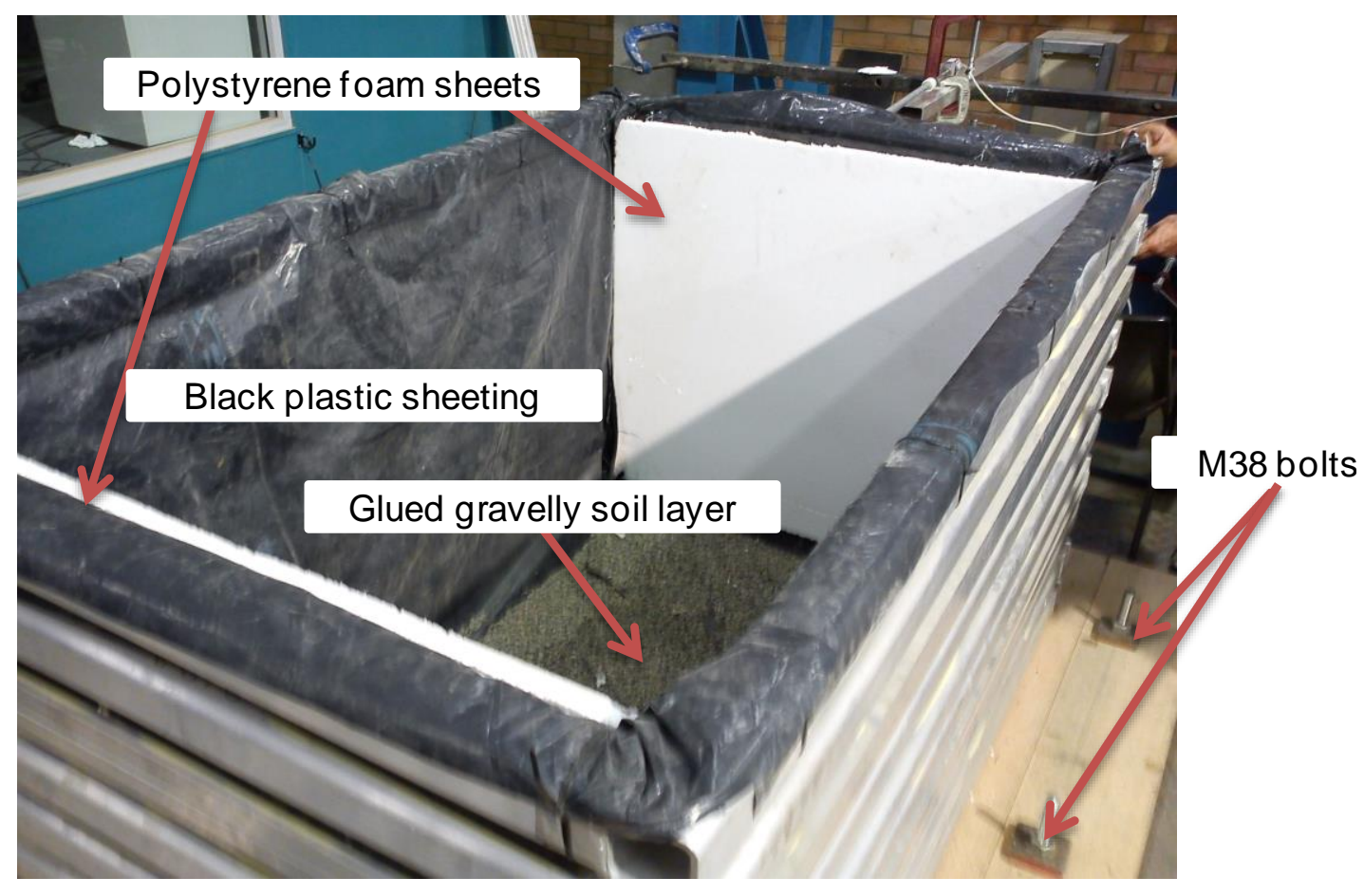

Figure 12: Various components of the secured laminar soil container on the shaking table 
Table 1: Scaling relations in terms of geometric scaling factor $(\lambda)$

\begin{tabular}{|l|c|l|c|l|c|}
\hline Mass Density & $\mathbf{1}$ & Acceleration & $\mathbf{1}$ & Length & $\boldsymbol{\lambda}$ \\
\hline Force & $\boldsymbol{\lambda}^{\mathbf{3}}$ & Shear Wave Velocity & $\boldsymbol{\lambda}^{\mathbf{1 / 2}}$ & Stress & $\boldsymbol{\lambda}$ \\
\hline Stiffness & $\lambda^{\mathbf{2}}$ & Time & $\lambda^{\mathbf{1 / 2}}$ & Strain & $\mathbf{1}$ \\
\hline Modulus & $\boldsymbol{\lambda}$ & Frequency & $\lambda^{\mathbf{1 1 / 2}}$ & EI & $\boldsymbol{\lambda}^{\mathbf{5}}$ \\
\hline
\end{tabular}


Table 2: Dimensional characteristics of scale model considering different scaling factors

\begin{tabular}{cccccccccc}
\hline $\begin{array}{c}\text { Geometric } \\
\begin{array}{c}\text { Scale } \\
\text { factor }\end{array}\end{array}$ & $\begin{array}{c}\mathbf{B}^{\prime} \\
(\mathbf{m})\end{array}$ & $\begin{array}{c}\mathbf{L}^{\prime} \\
(\mathbf{m})\end{array}$ & $\begin{array}{c}\mathbf{W}^{\prime} \\
(\mathbf{m})\end{array}$ & $\begin{array}{c}\mathbf{D}^{\prime} \\
(\mathbf{m})\end{array}$ & $\begin{array}{c}\mathbf{H}^{\prime} \\
(\mathbf{m})\end{array}$ & $\begin{array}{c}\mathbf{D}^{\prime}+\mathbf{H}^{\prime} \\
(\mathbf{m})\end{array}$ & $\begin{array}{c}\text { Volume } \\
\left(\mathbf{m}^{\mathbf{3}}\right)\end{array}$ & $\begin{array}{c}\text { Weight } \\
(\mathbf{k g})\end{array}$ & $\begin{array}{c}\text { Overturning } \\
\text { Moment } \\
(\mathbf{k N . m})\end{array}$ \\
\hline $\mathbf{1 : 1}$ & 12 & 60 & 36 & 30 & 45 & 75 & 64800 & $0.95 \mathrm{E}+8$ & $1.40 \mathrm{E}+10$ \\
\hline $\mathbf{1 : 1 0}$ & 1.20 & 6 & 3.60 & 3 & 4.50 & 7.50 & 64.80 & 95256 & 1400 \\
\hline $\mathbf{1 : 2 0}$ & 0.60 & 2.40 & 1.80 & 1.50 & 2.25 & 3.75 & 8.10 & 11907 & 89.50 \\
\hline $\mathbf{1 : 3 0}$ & 0.40 & 2 & 1.20 & 1 & 1.50 & 2.50 & 2.40 & 3528 & 17.30 \\
\hline $\mathbf{1 : 4 0}$ & 0.30 & 1.50 & 0.90 & 0.75 & 1.12 & 1.87 & 1.01 & 1488 & 5.60 \\
\hline $\mathbf{1 : 5 0}$ & 0.24 & 1.20 & 0.72 & 0.60 & 0.90 & 1.50 & 0.51 & 762 & 2.30 \\
\hline $\mathbf{1 : 1 0 0}$ & 0.12 & 0.60 & 0.36 & 0.30 & 0.45 & 0.75 & 0.06 & 95 & 0.15 \\
\hline
\end{tabular}

